\title{
Navigating emergence and system reflexivity as key transformative capacities: experiences from a Global Fellowship program
}

\author{
Michele-Lee Moore $^{1}, \underline{\text { Per Olsson }}^{2}, \underline{\text { Warren Nilsson }}^{3}$, Loretta Rose $^{4,5}$ and Frances R. Westlev ${ }^{6,7}$
}

\begin{abstract}
The distinction between adaptive and transformative capacities is still not well understood, and in this study we aimed to build a transformative learning space to strengthen transformative capacities. We proposed that two capacities will be essential to transformation: the capacity to navigate emergence and cross-scale systems reflexivity. We outline our efforts to design and deliver a Global Fellowship program in social innovation, intended to strengthen these two capacities among practitioners already engaged in socially innovative work. Results indicated that the concepts, frameworks, and experiences introduced through the Fellowship led to four key insights about these capacities. Firstly, individual Fellows and their organizations were able to see some complex system dynamics that were previously invisible, which in turn, allowed Fellows to see the distribution of resources and agency across the system in new ways. Secondly, engaging with diversity is essential in social innovation and transformative change processes, and system reflexivity aided in doing this. Additionally, Fellows indicated they were able to identify different kinds of opportunities and the generative potential that can lie within social-ecological systems. Lastly, the findings demonstrate the challenging nature of crossing scales and how a transformative space, such as a Fellowship, helps to practice the experience of contestation, unpredictability, and the uncontrollable dynamics of transformation and social innovation.
\end{abstract}

Key Words: complex systems; emergence; Fellowship; institutional work; resilience; social innovation; systems change; systems entrepreneurship; systems reflexivity; transformations to sustainability; transformative capacities; transformative spaces

\section{INTRODUCTION}

More than six years ago, a group of scholars embarked on an initiative to design and deliver a Global Fellowship program based on the latest research on social innovation, social-ecological resilience, transformations to sustainability, and complexity thinking. The aim was to support and strengthen the ongoing development and capacities of individuals and organizations working to generate social innovations and systemic change that would build resilience of social-ecological systems. To accomplish this, we sought to create a transformative space for learning. Philanthropic foundations have invested in creating numerous social innovation Fellowship programs in recent decades (e.g., Ashoka Fellows, Acumen Fellows, Echoing Green Fellowship, see also Lamb 2016). Amidst this crowded space of Fellowships, all promising to accelerate the impact of ideas, this Fellowshipfunded by the Rockefeller Foundation - was designed to serve a specific niche.

With the focus on mobilizing and translating knowledge associated with the specific theoretical underpinnings of the program, we adopted a definition of social innovation for transformation that involved shifting the authority, resource flows, power, norms, values, and beliefs, and the social-ecological relationships that underpinned the current problem domain in which a Fellow was engaged (see Westley and Antadze 2010, Avelino et al. 2017, Olsson et al. 2017). The theoretical orientation toward systemic, transformative change or "systems entrepreneurship" differs from other approaches and Fellowships for social innovation which are more closely aligned with neoliberal market logics regarding enterprise, hybrid private organizational forms, and accessing global economies as "the" social innovation itself (see Nicholls and Teasdale 2017 for a fuller discussion). Additionally, the focus on creating a safe space for transformative learning experiences differs from other Fellowships because they tend to focus on the individual's leadership and growing the market or appeal of their innovative initiative, while this Fellowship focused on mindsets and the agency needed to navigate complex system dynamics.

Previous research has investigated the capacities needed for social innovation and transformation, the results of which have revealed at least three main findings that informed the design of the Fellowship. Firstly, transformative agency - that is, the agency required to shift systems through any transformative change process - is distributed (Olsson et al. 2006, Lawrence et al. 2011, Westley et al. 2013). As early as four decades ago, Burns (1978) argued that organizational leaders and followers had a symbiotic relationship that was necessary to achieve societal transformations, but these ideas seemed to be buried by an overemphasis on individuals as strong leaders in organizational and leadership studies (Burnes et al. 2016). However, evidence increasingly indicates that systemic social innovation and transformation processes do not occur due to the activities of only a single leader or "hero-preneur"; rather, it is through distributed agency, "produced through the strategies of a number of actors, each of whom takes actions that help the system progress through different stages of innovation and transformation" (Westley et al. 2013:2; see also Garud and Karnoe 2005, Hahn et al. 2006, Olsson 2017). Therefore, any attempt to strengthen transformative capacities needs to consider actors as embedded within organizations and networks rather than viewing them only as the individual themselves.

Secondly, several strands of scholarship that have focused on transitions management, resilience, and innovation process studies have proposed that transformation processes do not occur

\footnotetext{
${ }^{1}$ Stockholm Resilience Centre, Stockholm University, Stockholm, Sweden, ${ }^{2}$ Stockholm Resilience Centre, Stockholm University, Sweden, ${ }^{3}$ University of Cape Town, ${ }^{4}$ Coracle Consulting, ${ }^{5}$ Bertha Centre, Graduate School of Business, University of Cape Town, ${ }^{6}$ Waterloo Institute for Social Innovation and Resilience, ${ }^{7}$ School for Environment, Enterprise and Development, University of Waterloo
} 
in a single event; rather, they involve multiple phases (Quinn 1985, van de Ven 1986, Rotmans et al. 2000, Olsson et al. 2004, van Driel and Schot 2005, Moore et al. 2014, Westley et al. 2017). Different processes and phases of transformation will then require different strategies (Dorado 2005, Olsson et al 2006, Biggs et al. 2010, Westley et al. 2013).

However, these diverse strategies and skills relate to a third key finding, regarding transformative capacity. Some debate persists in the literature about the distinctions between adaptation and transformation, and thus, the capacities needed if deliberately trying to achieve either one. Furthermore, one group of scholars use the term transformative adaptation to suggest that transformation of social, political, and economic structures that produce marginalization and inequality (O'Brien 2012, Eriksen et al. 2015, Pelling et al. 2015) is a necessary precursor to adapting to other types of change, such as climate change. For our purposes here, and in keeping with much of the existing resilience and social innovation scholarship, we define adaptation as the capacity of a system to adjust its responses to changing external drivers and internal processes and stay on the current pathway (Smit and Wandel 2006, Tschakert and Dietrich 2010, Park et al. 2012), and transformation as the capacity to create entirely new systems and pathways while simultaneously challenging or breaking down aspects of the existing system (Chapin et al. 2010, Moore et al. 2014, Goepel 2016, Olsson et al. 2017, Westley et al. 2017).

In adopting these definitions, though, several scholars have come to recognize that the distinction between the capacities that allow for adaptation and those capacities that allow for transformation is still not well understood (Brown 2015, Eakin et al. 2016, Coloff et al. 2017). Moreover, a recent study by Marshall et al. (2012) determined that although some capacities for adaptation and transformation may overlap, adaptive capacities can, at times, also hinder the capacity to transform. Recognizing this challenge meant that at this stage, the best option for the Global Fellowship program was to propose and test different capacities based on theoretical understandings of what is needed in transformation and what is different from adaptation. Therefore, we sought to explore two capacities that could be critical for systemic social innovation and transformation: (1) the ability to navigate emergence, and (2) enhancing system reflexivity.

With three cohorts of the Global Fellowship program now complete, we seek to share our first attempt at building a transformative learning space through a Global Fellowship program on social innovation. First, we explain the conceptual antecedents that informed the design and delivery, including a discussion on the capacities related to emergence and system reflexivity from a variety of resilience, complexity, and organizational development literatures. Next, we provide a general description of the Fellowship program in our Methods and introduce the developmental evaluation approach that was used before moving to identify the insights gained about the design of the Fellowship and about the systemic impacts, if any, that the Global Fellows had as a consequence of applying the theoretical concepts and theories to their ongoing innovation work.

From our analysis, we contend that the Fellows' engagement with the theory revealed four main themes that were deemed essential for navigating emergence and enhancing system reflexivity:
1. altering or improving the ability to "see" complexity and the agency that can be mobilized within a complex system;

2. engaging with diversity;

3. recognizing the different forms that opportunity may take within a system and the generative solutions that emerge from a human-in-nature perspective; and

4. identifying micro-macro or cross-scalar relationships.

Social innovation Fellowships funded by foundations have emerged as phenomena themselves, but thus far have generated limited to no scholarly interest. Consequently, little has been theorized or analyzed empirically about the programs. Scholarship on transformative learning in academic settings has yielded insights about pedagogy and the enjoyable experiences of students (Mezirow 2000, Taylor 2007), and research has been conducted on the value of complex systems thinking approaches (e.g., see the UK's Open University for a long history on such programs, Reynolds and Howell 2010, Sweeney and Meadows 2010). All this background research could be used to inform the process, yet existing knowledge hardly provided a prescription for how to design a transformative space and deliver a Global Fellowship program, and link to complex social-ecological initiatives, such as those working to achieve the UN Sustainable Development Goals. Through sharing the results of the Global Fellowship program, we aim to initiate a discussion about the possible impacts of such a program, particularly for building transformative capacities related to emergence and system reflexivity. Such a contribution can advance the understanding of how to intentionally design transformative spaces to strengthen transformative capacities of actors deliberately engaging in systems change initiatives that aim to address global socialecological challenges (see Rockström et al. 2009 or Steffen et al. 2015 for detailed discussions on global social-ecological challenges).

\section{NAVIGATING EMERGENCE AND SYSTEMIC REFLEXIVITY}

Emergence and emergent structures are widely recognized within the literature on complex systems, and the concept of emergency has been widely debated both for its definition and with regards to what "it" is or how it can be understood (e.g., Kauffman 1995, Goldstein 1999, Holland 2000). At the heart of this debate lies a tension between reductionism and holism ontologies. More holistic accountings of complexity view emergence as novelty arising - a feature or element not previously present in the system - as a result of the dynamic interaction of two or more "parts" of the system so that a new "whole" is qualitatively different from before (Mitleton-Kelly 2003, Sawyer 2005, Page 2015). Note that qualitatively different does not necessitate that the whole is more than the sum of the parts, just different (Corning 2002). Reductionist perspectives have struggled to explain emergence, though, perhaps because the holistic perspective and the idea that microlevel interactions (or the "parts") can lead to different mesolevel or macrolevel properties make emergence sound as though "It's not magic... but it feels like magic" (a quote attributed to Doyne Farmer). Reductionist science is predicated on the notion that any whole or system can be explained by the properties of its parts, as opposed to the parts equalling something novel that cannot be explained by their individual components (Page 
2015). From that perspective, the unpredictable nature of emergence itself has been viewed not as an actual dynamic that exists but simply as a shortcoming of the "state of the art in science and not of some superordinate property in nature itself" (Corning 2002:20), meaning that reductionist science just cannot explain it yet.

For the purpose of this discussion, and given the essential nature of novelty to the practice of social innovation, we adopt the more holistic view of emergence rather than the reductionist one, emphasizing the synergistic effects that create novelty within systems. We also recognize, as Corning (2002) points out, that despite all the careful debate, the term "emergence" is often used simply as a synonym for the appearance of a trait or growth without any reference to the idea of a relationship between parts unpredictably contributing to a qualitatively different whole. This is problematic in that the consequence of ignoring how to generate, respond, and then navigate emergence of a qualitatively different whole seems the antithesis of transformative social innovation processes. However, we recognize that outside the academic world of theory, and in the world of social innovation practice, the concept itself may be helpful only for explaining certain dynamics after they have occurred if more effort is not invested in building capacities to recognize and navigate emergence as it happens.

Thus far, even the scholarship most deeply engaged in applying complexity theory to innovation practice, such as research on organizational management and strategic leadership (e.g., Burnes 2004, Uhl-Bien et al. 2007, Burnes et al. 2016), has been unable to go beyond identifying that emergence is something with which managers and organizations need to reckon. It is one thing to state that emergence exists in complex systems but another thing entirely to navigate through the experience of emergence while deliberately trying to address the systemic nature of today's most intractable social-ecological challenges. Moreover, questions remain about how to navigate emergence if, as Westley et al. (2013) state, transformative agency is distributed.

While we do not purport to have definitive answers, we adopted a premise for this program that one capacity for this navigation involves system reflexivity (Voß et al. 2006), thereby seeing these two capacities as linked. While social innovation researchers have yet to take up the concept of reflexivity directly, the scholarship is increasingly emphasizing that social innovation involves institutional disruption and re-creation. Or, as Unger (2013:2) describes it, as the attempt "to resist and subvert the dictatorship of no alternatives...in the direction of an enhancement of agency in all domains of social life of the capacity for invention and selfdirection." We contend that at the heart of the disruptive process of social innovation lies a need for a type of institutional reflexivity; that is, the capacity to see, interrogate, and reimagine the taken-for-granted structures that sustain current systems and people-planet relationships.

From this perspective, social innovation is clearly not just about the act of invention but also about the "institutional work," a burgeoning area of research in sociology and organization studies (Lawrence and Suddaby 2006, Lawrence et al. 2009, 2011). Institutional work researchers explore the relationship between structure and agency made manifest through "the efforts of individuals and collective actors to cope with, keep up with, shore up, tear down, tinker with, transform, or create anew the institutional structures within which they live, work, and play, and which give them their roles, relationships, resources, and routines" (Lawrence et al. 2011:53). But just as with emergence, institutional work theories also must confront the problem of embedded, distributed agency (Seo and Creed 2002, Garud et al. 2007). A core premise of institutional theory in sociology is that most institutional rules, norms, and beliefs are cognitively submerged or taken for granted (Berger and Luckmann 1966). How then do individuals and collectives - embedded in this opaque worlddevelop intentionality and capacities for transforming social structures that are difficult to apprehend in the first place? In response to this question, some scholars are beginning to wrestle with the nature of institutional reflexivity (e.g., Suddaby et al. 2016, Vink and Koskela-Huotari 2017).

Writing through an institutional lens, Suddaby et al. (2016:229) define reflexivity as "an individual's general awareness of the constraints and opportunities created by the norms, values, beliefs and expectations of the social structures that surround them." A number of theorists have argued that this kind of reflexivity has dramatically increased during the historical period of modernity due to globalization, technology, and the overall speed of cultural change (Giddens 1991, Beck et al. 1994, Adams 2003, Beck et al. 2003, Archer 2010), all of which contribute to more regular breaches of the taken-for-granted ways of operating (Akram and Hogan 2015).

However, what is most striking about both the reflexivity and the institutional work literatures is that neither takes up the question of pedagogy. That is, if system reflexivity is a key capacity, how might we intentionally cultivate it? The picture painted in the literature is primarily a static one, as though reflexivity at any given point in time is determined by historical forces (e.g., Giddens 1991, Archer 2010) and/or the given structural positions and social skills of individuals (Suddaby et al. 2016). While there has been some recent movement toward theorizing reflexivity as a dynamic process (Vink and Koskela-Huotari 2017), there is little research into how actors might intentionally cultivate such a process with the goal of deepening system reflexivity over time, and again, particularly if agency is indeed distributed across numerous actors who are acting in both coordinated and uncoordinated ways (DiMaggio 1988, Bang 2004, Lawrence et al. 2011). Moreover, we assert that this literature neglects the opportunity to include that a deeper reflexive capacity will need to focus not just on social structures but on how social-ecological structures and systems change. It has been well established that a transformation in people-planet relationships is needed (e.g., Westley et al. 2011, Feola 2015, Olsson et al. 2017) in order to create a just and sustainable future, and we contend that deeper systemic reflexivity will be needed to navigate such transformational change processes in the institutions that shape social-ecological relationships (see also Ostrom 2005) and will be an essential capacity for social innovation.

Many pedagogical theories and frameworks aimed, at least implicitly, at increasing reflexivity have been explored in the organizational development and learning literatures, but their application to system transformation is under-researched (Senge et al. 2015). Moreover, a number of programs and process "tools" for practitioners have been developed to increase reflexivity of a 
system (Sweeney and Meadows 2010), including but not limited to various innovation lab processes such as Theory $\mathrm{U}$ (Scharmer 2009), Appreciative Inquiry (Cooperrider and Srivastva 1987), and dialogue processes (Bohm 1996, Ellinor and Gerard 1998, Isaacs 1999). These processes tend to use a collaborative approach to push participants past their initial assumptions and conditioning in order to foster a deeper awareness of structural constraints and possibilities rooted in the system.

While these programs and approaches may be markedly successful at raising awareness of complexity, those individuals who start paying attention may still default to existing problem-solving tools. However, the reality with emergent dynamics and the "novel" or qualitatively different whole that arises is that existing tools may no longer suffice. Therefore, much work remains to be done to understand how a sustained, embedded type of reflexivity can be nurtured across wide bands of any given social-ecological system-beyond a given organization, issue, or time period. Drawing on multiscalar change heuristics in the transitions (Geels 2002, Smith et al. 2010) and resilience (Gunderson and Holling 2002, Cash et al. 2006, Cumming et al. 2006, Wyborn and Bixler 2013) literatures, we developed the Global Fellowship program with the assumption that nurturing cross-scale reflexivity is key to expanding the systemic impact of reflexive pedagogies. These heuristics focus on interaction between scales as a key driver of both innovation and resilience. In the Global Fellowship program, we sought to bring to bear many of the same kinds of reflexivity tools and frameworks previously mentioned but with an emphasis on using them specifically to develop and deepen cross-scale relationships.

\section{METHODS: OUR APPROACH TO THE FELLOWSHIP, ITS DESIGN, AND EVALUATION}

The Global Fellowship program was initially proposed by the Waterloo Institute for Social Innovation and Resilience and the Stockholm Resilience Centre to the Foundation. The Rockefeller Foundation has a long history with investing in ideas that it, as an organization, has determined to be innovative. As with all philanthropy, the results have been both widely acknowledged for their importance and heavily critiqued for the powerful diffusion and transfer of north-south ideas (e.g., Abel 1995, Jones and Rahman 2009, Youde 2013). The team kept these critiques at the forefront as we shaped the design.

After a year-long design process, a one-year pilot Fellowship was launched in 2013. Additional partners joined at the end of year 1 -Bertha Centre, University of Cape Town and the Centre for Global Studies, University of Victoria - and these organizations were awarded funding for two more years of the program.

Initially, Fellows were nominated by the Foundation program managers, focusing on three specific thematic areas in which the Foundation either had, or continued to, award grants, including Digital Jobs Africa, Asian Cities Climate Change Resilience, and Transforming Health Systems. In years 2 and 3, nominations were expanded so that anyone in the networks of the Foundation, its partner agencies in development, the delivery team and its partners, and any of the alumni Fellows and their networks could nominate Fellows to attend the program. The thematic focus for the year 2 and 3 cohorts was more general, emphasizing social innovation and social-ecological resilience.
Nominees were invited to submit a one-page application letter indicating why a Fellowship program may be of interest, a curriculum vitae, and a letter of support from their organization indicating that the organization shared an interest in the concepts and theories of social innovation and resilience, and that the time away from the organization for learning would be supported by the organizational leadership. In year 1, 18 Fellows were accepted, and in years 2 and 3, 21 Fellows were accepted for each cohort. In years 2 and 3, different individuals from the Foundation also attended different modules. The geographic locations of Fellows' organizations, gender of participants, and type of organizations to which Fellows' belonged when they applied to the program are highlighted in Fig. 1, 2, and 3, respectively. Typically, Fellows had some type of existing experience with systems change (even if the terminology used to describe their work was quite different), and they had sufficient authority within their organizations or networks to potentially implement changes if needed, if they wanted to test or apply new ideas. Educational backgrounds varied from very little formal education to higher levels of education, and ages ranged such that some people were in their early careers, while some were nearing the end of their careers. English was a requirement for the program, but comfort in using English did inevitably vary.

Fig. 1. Geographic location of Fellows' organizations at time of acceptance.

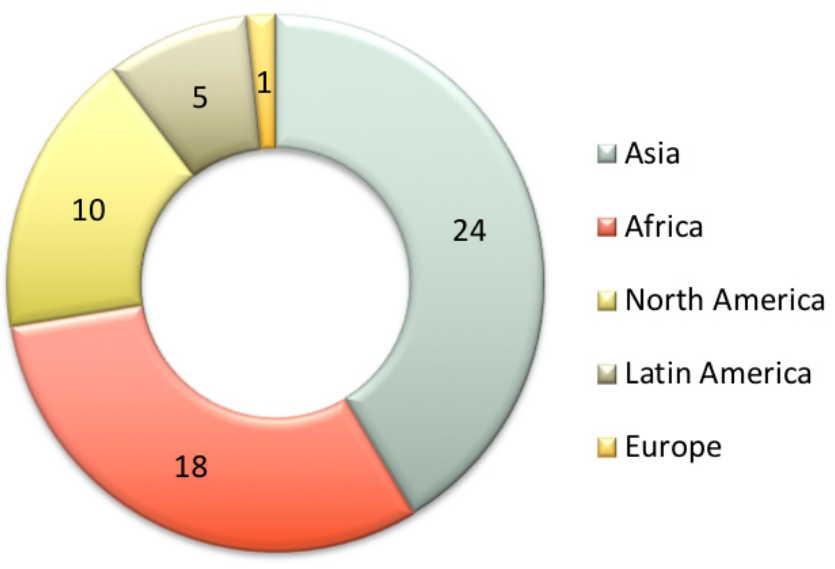

Fig. 2. Gender distribution of Fellows over three cohorts.

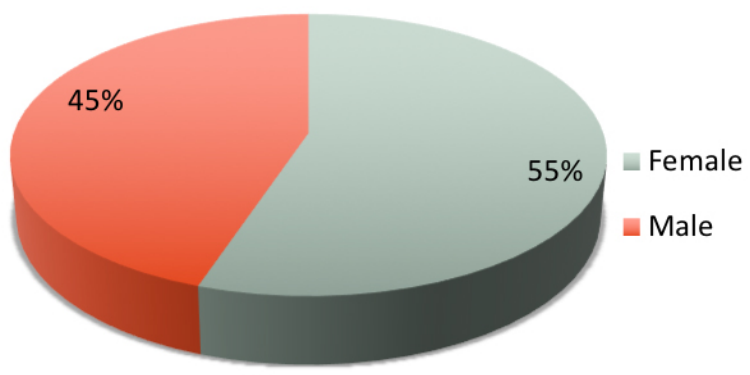


Fig. 3. Type of organization in which the Fellow was affiliated at the time of beginning the program.

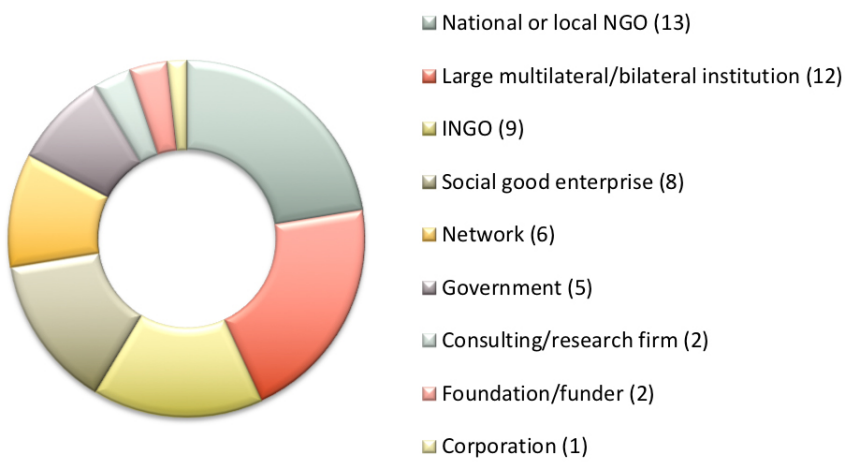

\section{Pedagogy}

Although not explicitly adopted, the pedagogical design of the Global Fellowship learning experience most closely aligned with the principles described in transformative learning theory (Mezirow 2000, Taylor 2007). For instance, Mezirow (2000) describes the importance of transforming perspectives by undertaking a critical assessment of epistemic, sociocultural, or psychological assumptions; examining one's self, including feelings, roles, and competencies; exploring and provisionally trying new roles, relationships, and actions; acquiring new knowledge and skills; and building competence and confidence in new roles and relationships (see also Taylor 2008). The idea is that some kind of cognitive dissonance regarding what one believes and experiencing it as no longer making sense is at the heart of a transformative learning experience. This principle of working to dismantle cognitive lock-ins, in a safe space, with support if needed, to help each other break down barriers and innovate a fundamentally different, more sustainable and just future was a transparent intention of the design. However, although transformative learning literature describes these principles, and relevant case studies have documented how individuals may have appreciated the experience, this still provided little prescriptive assistance in terms of actually designing a Global Fellowship, including the content.

Given the value of experiential learning (Torbert 1972, Kolb and Kolb 2005), but also the strength that lecture-knowledge transfer styles still hold for performing and enlivening new ideas and concepts, we deliberately incorporated a diversity of pedagogical tools in each module. Each module location was carefully selected based on the relevance of field study visits to the concepts and to the arc of the program. The intention was to immerse the Fellows in a specific social-ecological challenge and reflect on the learning and its meaning with local individuals, organizations, and networks working toward systems change. Therefore, modules included experiential learning with practitioners in the locations where we met, and these locations were carefully selected for the potential of the relationships that could be explored. However, separate from the local engagement, we also incorporated peer coaching among the Fellows, drew on presentations by the Fellows about their own work as "live" case studies to analyze using complex systems and resilience concepts, and included role playing, artistic expression, storytelling, and conventional lecture styles throughout the program.

For the sake of length and given the purpose to explore the potential of creating space for building transformative capacities, describing the entire content of each module is not possible here. However, examples of key concepts and exercises are shared in relation to specific thematic results. Additionally, much of the actual content has been shared through online learning platforms (see, for example, WISIR Learning Modules on Social Innovation for Complex Problems and SiG Knowledge Hub). Although a framework and an extensive design phase established the flow and arc of the program, the design of individual modules was still partially emergent each year in response to the context of where each module was held and which local partners engaged with us, as well as the interests of the Fellows' themselves, and as a result of adapting our own approach based on feedback we received from the developmental evaluator. These changes were made but with attempts to maintain the overall integrity of key goals that underlay our design thinking, which was that the program served to:

- build an indepth understanding of human conditions on the planet and how humanity is an integral part of, and is fully dependent on, functioning ecosystems;

- develop skills in systems entrepreneurship that enable socially innovative initiatives for transformative change to sustainability;

- support the identification and creation of social innovations with the potential to contribute to transformations;

- develop skills in linking innovations to necessary social, political, and economic resources to scale solutions in ways that strengthen the relationship between people and planet; and

- build networks of change agents that span regions, sectors, and problem domains for new approaches to social innovation and transformations to sustainability.

\section{Developmental Evaluation Framework}

Traditional tools of program evaluation tend to focus on evaluating the implementation of a particular program and whether quantifiable targets have been reached. Typical evaluations may also assess cause-and-effect relationships between the program components and outcomes to capture lessons learned about successes and challenges (Quinn-Patton et al. 2016). However, these approaches tend to be based on linear logic. Given the experimental nature of the approach to the Global Fellowship program, and the theoretical orientation toward complexity, which emphasizes nonlinear and unpredictable dynamics of systems, we adopted a developmental evaluation approach.

Developmental evaluation is intended to be an iterative process that studies an innovation as it is carried out, and is rooted in complexity thinking (Quinn-Patton 2011, Langlois et al. 2012, Dickson and Saunders 2014). Consequently, we did not have fixed measures we were seeking (e.g., X number of people completed the Global Fellowship program) since these were not helpful in determining if we were strengthening social innovation and 
transformative capacity. Instead, we used qualitative evaluations that sought information about issues that related to social innovation and the core theoretical concepts we introduced. As just one example, given the focus on cross-scale impacts in understanding social innovation that creates systemic change, the evaluations explored whether Fellows had built new networks or reconfigured existing networks to better cross scales that mattered to their problem domain, and whether concrete evidence within their networks could be found. We were not interested in the number of connections or the specific type; that is, we did not predetermine that connections had to include one type of organization, but emphasized diversity and defining the scale boundary.

\section{Data collection and analysis}

Numerous data collection methods were used over the course of the three years of the program delivery. Structured online surveys were completed by Fellows after each module, which focused on the value (or not) of specific concepts and session designs, to provide an immediate feedback mechanism on content and pedagogy. Fellows were also encouraged to provide ideas for future modules so that the design could be shaped according to interests and needs of the Fellows, which resulted in some different content in different cohorts. Indepth, semistructured interviews were also conducted with Fellows at two different points in the Fellowship journey. The first interview was conducted approximately halfway through the program (after module 1 or 2, depending on the availability of the Fellows and their response times), and after the program was completed (some Fellows were interviewed two years after completion). The first interview sought to understand early applications of the concepts, what Fellows were sharing within their networks and for what purpose, and how the theory may be changing specific practices. The second interview focused on the longer term impacts of the program in supporting transformative capacities for systems change. In year 1, interviews were also conducted with Foundation officials and program managers, as well as with the delivery team members, while year 2 and 3 interviews focused on the Fellows only. In the end, more than 47 interviews were conducted (not all Fellows in all cohorts responded to interview requests). The developmental evaluator in year 1 attended a couple of days in module 1 and module 4. After changing evaluators in year 2, the developmental evaluator attended six of the seven modules in years 2 and 3, thus using direct observation to inform the findings. Focus group discussions took place in year 1 and 2, and filmed interviews also took place with those cohorts. Furthermore, the evaluator tracked news of the Fellows after they completed the program by observing the shared WhatsApp and Facebook discussions among Fellows and the official news that Fellows and their organizations shared with each other through email about projects, awards, and career changes. In years 2 and 3 , with the new developmental evaluator, questions were also framed to reinforce learning by the Fellows, not just create data for the team. Many Fellows mentioned this helped them remember learnings and that the evaluation discussions provoked them to go further in their thinking.

Data were initially open coded and then based on a modified framework of Corbin and Strauss' (2008) axial coding approach, using the general categories of reactions and learning (relationship to material/content), behavioral changes (individually, organizationally, or as networks), and results and impacts. The categories were established based on the scholarly interests regarding transformative capacities but were also shaped by the need to report back to the Foundation as a funder and meet their programmatic interests and requirements. Detailed codes were then developed within this framework, which led to theoretical and conceptual themes after cohort 2 , which were then continually tested, refined, and altered as necessary as data collection and analysis continued in year 3 .

\section{RESULTS AND DISCUSSION}

\section{Building reflexivity and navigating emergence}

Our findings revealed that our attempt to create a transformative space in order to strengthen capacities for navigating emergence and building systems reflexivity produced four main insights for Fellows. We contend that these themes provide a more detailed understanding of what transformative capacities could entail. As novel or qualitatively different interactions come to bear through emergence, and systems reflexivity is enhanced, Fellows and transformative agents come to better (1) see how and where the agency that is distributed across the system can be mobilized and for what purpose, (2) understand how to engage with difference; that is, diverse worldviews, organizational structures, cultures, and more, (3) recognize how to build opportunity for systemic change in varied contexts, and (4) identify the cross-scale relationships that will ultimately matter to whether or not transformative change happens.

\section{"Seeing" complexity and the agency that can be mobilized}

All the Fellows and the many candidates who applied to the program described the numerous, interrelated, complex problems they were attempting to address through their efforts to socially innovate. Despite the categorization of these problems as complex, though, many scholars and practitioners alike tend to use the term complex as a metaphorical or descriptive device (Burnes 2005) without applying complex systems theory and thinking.

Scholars often define complex systems more by their attributes rather than having a single, agreed upon definition-properties such as self-organization, feedbacks, emergence, nonlinearity, and more (Manson 2001, Page 2015). What this means for Fellows who are engaging in trying to deliberately change the dynamics that have created complex problems in the first place (Olsson et al. 2017), such as those who are trying to address integrated challenges such as the Sustainable Development Goals, is the need to understand that social-ecological systems behave in the following ways:

- Social and ecological systems are deeply intertwined (e.g., Folke 2006, Gual and Norgaard 2010).

- Change and surprise are expected and may unfold in ways that are fast or slow, or both types may happen at the same time (e.g., Galaz et al. 2017).

- The global and the local are connected in unexpected ways in distant places and over time (e.g., Cash et al. 2006, Crona et al. 2015). 
- True uncertainty is unavoidable (Polasky et al. 2011).

- Systemic change does not proceed in a linear manner and may be both planned and emergent (e.g., Biggs et al. 2012, Moore et al. 2014).

- Thresholds and tipping points exist, and crossing them may lead to changes that are irreversible (e.g., Norström et al. 2009, Lade et al. 2013, Rocha et al. 2015).

For the purpose of building capacity to "see complexity," we emphasized two aspects in particular in our design. Firstly, given that change is understood from this perspective as nonlinear and emergent, scholars have invested considerable effort in describing and defining the multiple phases that a transformation process could involve (see for instance, Geels 2002, Olsson et al. 2006). As previously mentioned, each phase during a transformation will involve different structures and processes, and thus will require different strategies and capacities (Westley et al. 2013, Moore et al. 2014, Olsson et al. 2014). Secondly, scholars have previously described the nature of teleconnections-the unexpected ways that connections across large or distant scales can lead to unintended consequences that amplify or dampen both the complexity of challenges and the impact of the innovation that may be created to resolve them (Eakin et al. 2009, 2017, Galaz et al. 2011). The linkages are even more complex when they are not just the result of human-human interactions but human-ecosystem-human interactions. For example, Keys et al. (2016) demonstrate how water management activities in one place can affect natural evaporation rates, which in turn, alter the amount of precipitation that falls elsewhere, and thus affects humans in a distant watershed, even though the people in each place never directly interact. These teleconnections, along with the numerous more proximal connections to a Fellow's work, may be made seemingly invisible by structures and processes in place. Therefore, building capacities for transformation may involve developing an ability to make these relationships more visible.

Based on these two aspects, the Fellowship program was designed to ensure that Fellows understood both the phase of the problematic system they were challenging and working to break down, and the phase of the alternative system or innovative initiative they were attempting to build up, using heuristics such as the adaptive cycle and stability landscapes (see Scheffer et al. 2001, Gunderson and Holling 2002 for more detailed discussions on each of these concepts). An emphasis was placed on giving explicit attention to the capacities or strategies that are strengths for the Fellows as individuals and that lie within their organization or networks of transformative agents, while considering what other phases will still be ahead (e.g., Biggs et al. 2010, Westley et al. 2013). Additionally, Fellows then analyzed the possible teleconnections to other scales that may be affecting all the strategies and efforts being made through systems mapping.

Although exercises could open up new understandings, some Fellows were initially overwhelmed by the connections and issues they had not previously considered. Part of this may have related to the surfacing of uncomfortable ideas. One Fellow noted:

What people want in their lives is security, certainty, safety; and when they're living this hard experience of trying to do social change it's hard, and they don't want to hear that that's part of it, too. So, their first reaction to these ideas is defensive.
Although the evaluation feedback immediately after a module would capture this frustration, later surveys and interviews revealed that understanding the different phases that the frameworks identified - such as the adaptive cycle from resilience theory - and the systems mapping were both powerful tools. One Fellow reflected:

\section{It made a huge change, to be more understanding of how the system works, and not just talk about the bad things about it-but: how can we navigate?}

Another stated:

I'm more comfortable now with the fact that I'm a fish out of water in most circumstances. I understand where I am in the adaptive cycle, even though my client may be in a different place. I regularly think about this idea of systems constantly being in flux.

Our findings indicate that Fellows are beginning to ask different questions and to consider the dynamics of their systems of interest from new perspectives. The impact this knowledge has on how they undertake socially innovative initiatives and whether this ultimately has a different kind of systemic impact is not likely to be known for a longer period of time, if it can be measured at all. However, we suggest that the concepts may help make it more clear to Fellows how they can mobilize their own and others' agency in the system.

As one example, one Fellow who was working in a small, local NGO in central Africa came to understand through the systems mapping exercises that broader political issues were affecting all of her efforts. Having realized this, she deliberately chose to shift her focus on engaging with political leaders, but when she tried to engage there, she found that deeper norms and larger institutional structures about gender roles limited the impact that she wanted to achieve. Less than a year later, this prompted another shift, and she began working with an international organization, responsible for developing the entire region's approach to gender issues. The Fellow is clear in interviews that she chose to engage in different parts of the system, seeking different leverage points, to alter the conditions that were creating the problems in the first place, and she spent time with the next cohort of Fellows explaining her strategies and implementation of the concepts. Another Fellow shared how complex systems thinking had helped her see nuanced connections between food security issues, family size, and gender roles in her system, which she had not previously understood, again, providing evidence that the approach to her social innovation was changed in scope.

\section{Engaging with diversity}

Scholarship from across multiple disciplinary perspectives emphasizes the importance of diversity within a system - ranging from its role in ongoing functioning to adding creative tension and increasing the likelihood for new ideas. With regard to socialecological resilience, diversity can relate to functional diversity, and ensuring enough different actors or species carry out a diversity of tasks to ensure basic ecosystem functions and processes may be sustained, and response diversity, which refers to the variety of responses produced by the interplay of the living and nonliving world (Elmqvist et al. 2003, Luck et al. 2003). Diversity will also include social diversity, which can relate to personalities and how we interact with one another; cognitive and informational diversity, which refers to what individuals know 
and how they process different information; and values and worldview diversity, along with the various constructed categories of race, gender, sexual orientation, geography and place of birth, and more (Harrison and Klein 2007, Harquail 2010, CorderoRivera 2017).

When navigating transformative change processes, we expect that it would be easy to experience an interaction with an individual who has fundamentally different behaviors, identity, values, or worldviews as a conflict or a barrier to achieving the change. For some, the tension will be generative, but others may disengage and focus instead on allies or like-minded individuals, leading to a lack of engagement with the potentially generative space.

If diversity is essential for protecting a type of emergent potential and intelligence in the system, then having the skills to navigate experiences of diversity may be a crucial capacity for transformative change. Although no prescription exists for how to attempt to build this capacity, it seemed an essential opportunity to explore as we designed a transformative space. Thus, we created numerous activities across the Fellowship modules to engage with diversity constructions and the notion that these create lenses through which an individual or entire social group will view the world and other living and nonliving elements within it.

The exercises included role playing, self-evaluating learning preferences, specifically assigned a "lens" to adopt for a field site visit with a new organization, and analyzing a problem with different lenses, including social, cultural, technological, economic, environmental, and political lenses. The intention was to enhance the ability of Fellows to understand their own preferred and dominant lens but practice experiencing and engaging with others. Fellows were also introduced to various skills and practices such as mindfulness and improvisation to again reflect on their general approach and ways of viewing the world.

Fellows repeatedly pointed to the importance of these ongoing exercises as a chance to help them reorient their own thinking and to consider new approaches or new connections in their work. As one Fellow who worked for a large development agency explained:

One of the things that sticks with me is...is approaching a problem from multiple dimensions and many lenses; looking at approaching a particular problem in my space not from finance, but through other elements.... I do that now in a much more considered way than before. For example, I continue the weekly practice with my team of TED talks, looking at development beyond the financial lens, and being more thoughtful: Who are we choosing to work with? How are we choosing to work with them? So a lot of the approach to both my work and my team has been heavily influenced by the experience I've had in the Fellowship. In some ways, it's subtle, but I'm trying to work in a more holistic, multifaceted way.

Others discussed the need to make new links and build alliances that were atypical for them previously:

...we started to realize that we need to establish relationships with unlikely partners, and ones with whom we don't agree-like government, or risk-averse institutions - and start changing our mindsets; because we need to work together. Otherwise, there's no way to move the needle. We will not get to the next level unless we get connected to these unlikely partners.

The organisations I work with are trying to see why fewer girls are in technology and how we can change that? ...What if you start thinking about the other causes, things that surround girls, other things in the system in which girls live? So, is it just about providing girls with opportunities, or is it beyond just her? For example, I've worked on really getting solution creators to look at things like bringing together government and education, bringing girls from rural and urban areas-and what changes if you bring these different groups together? So, a deliberate mix of communities; and this has absolutely created different thinking patterns.

In addition, we observed that the network created through the Fellowship itself offered opportunities to practice engaging with diversity, given the global nature of the program and the different life experiences, ages, education levels, values, place attachments, organizational types, and more that were present within and across cohorts, along with the diverse locations and field studies involved in each module. As one Fellow commented:

Often, in my work, I think of how the Fellows would have looked at particular issue. The diversity of backgrounds and experiences brings incredibly rich thought resources to any problem we wish to address, without their being 'conditioned' by an ongoing work relationship.

Recognizing opportunity within a system and generative socialecological spaces

The notion of creating and introducing socially innovative initiatives into complex problem domains requires reflexivity about what is being introduced, by whom and for whom, why, when, where, and how. Many of the systems within which the Fellows worked were experienced as rigid, not open to innovations except those that further strengthened specific desired and dominant traits (such as reinforcing the power of the already powerful) or even oppressive or violent traits. Transformative change tends to be highly resisted for numerous reasons (e.g., Brown 2015, Burnes 2015, Eakin et al. 2016), and having a capacity distributed across various actors to navigate the resistance as it emerges could be expected to be important for systemic transformation, which is why we consider this capacity distinct from adaptive capacity.

We introduced three core concepts regarding emergent dynamics and navigating opportunities and resistance in different contexts, including (1) Dorado's (2005) framework about different strategic action in opportunity contexts that may appear transparent, hazy, or opaque (see also Westley et al. 2013), (2) bricolage-to emphasize that novelty can come from recombining existing elements in new ways (Westley 2013, Olsson et al. 2017), and (3) Kauffman's (2000) idea of the adjacent possible to again encourage reflexivity and awareness about the nearby possibilities with which to bricolage or that could serve as "attractors." As Mitleton-Kelly (2003) explains, the emphasis is about exploring 
the space of possibility to generate variety and novelty, and we add that this possibility space is expanded even more when socialecological relationships are taken into consideration. Most important is the interplay of all three of these constructs, given that the manner in which Fellows may undertake bricolage or what they can access in the adjacent possible is shaped by their context, which in turn is continuously reshaped by the Fellows' (and their organizations' and networks') actions. One Fellow stated, "I think more about systems and pulling different levers with different actors within the ecosystem," while another Fellow reflected:

\begin{abstract}
In the work I've been doing, I'm connecting people and building networks, either within or outside an organisation. So, it's a way of thinking: how could you get this kind of bricolage or this kind of initiative to pair up with something that looks totally different that people haven't thought of as being related to each other?
\end{abstract}

Two other Fellows recognized that recombining existing elements also means letting go of current configurations, patterns, and ways of doing but found that with some consideration, a thoughtful choice could be made about what they let go of, and what they held onto during the process.

\section{...I've realized that there are certain existing patterns in the society [where I work] that need to be released and re-formed in a different way. It (the Fellowship) has allowed me to think differently - realizing that it's $O K$ for things to fall apart at certain points, in order to reform in a different way, and that's a very different way of thinking.}

Our tendency is to look for elements that validate our assumptions. Front and center for me is the positive, religious influence [in the one of the field study visits] ...It's something that I just never thought could be used. We're at a state globally, where any religious influence is seen as a negative factor, and I've seen it as something detrimental because it inhibits questioning. But to see that the practices - at least to some extent - do ensure the effective functioning of that system leads me to question: How do we find and leverage those, instead of trying to throw it all out?

When attempting to take advantage of an emergent opportunity, it must also be acknowledged that this bears genuine risk, not just for the longevity or integrity of the socially innovative idea being introduced but for the personal safety of those mobilizing their own and others' agency in introducing it. Numerous discussions among Fellows raised questions regarding how to know when to take specific actions or exert agency, and when to observe system dynamics but not take action. Given that no one can truly predict the timing or write a formula for when specific strategies or capacities of transformative agents should be mobilized within complex systems, this highlighted uncertainties and security risks, both personally and within the system. One Fellow who was attempting to undertake change in an unstable, sometimes violent system state, posed many questions about when an action may have a positive impact and when it may be met with violence or may be co-opted so that the innovation is no longer possible, or even worse, further reinforces maladaptive dynamics already present within the system.
[Mine] is a country where we really need to be cautious who you speak to and where you speak; people literally are dropping dead for speaking out... Here, knowledge can kill you...I have to ask: when do I speak? To whom do I comment?

The Fellow continued:
...It's great applying all this theory, but because I'm in a country where there's basically no women's rights, my voice doesn't count... The opposition love that they have someone vocal (me), but this can present a threat. Being a threat will definitely expose me to being poisoned or being killed. So, I have to balance when to apply which theory, or how I have to delegate to my staff, and tailor those theories to the local mindset.

Identifying cross-scale relationships

Building awareness and engagement with micro-macro relationships can be part of building general system reflexivity, given that these relationships are sometimes unexpected, difficult to observe, and therefore, easy to neglect. Becoming attentive to both the potential impact that variables from other scales may have on the transformation process, and in turn, the consequences that a Fellow may trigger across scales, seems an essential capacity.

However, engaging with conceptual frameworks regarding scale also enables the opportunity to clarify whether the actions a Fellow is undertaking are having transformative impacts or not, and thus, what might be meant by the idea of "scaling for impact," which is a frequent mantra heard in social innovation scholarship. A variety of conceptual frameworks were used for these purposes, including Giddens' (1979) theory of structuration, layered with a micro, meso, macro framing, the multi-level perspective (Geels 2002), and a framework distinguishing between scaling out, up, and deep (Moore et al. 2015).

Lastly, we introduced the concept of organizational inscaping, defined as "surfacing the inner experiences of organizational members during the normal course of everyday work" (Nilsson and Paddock 2014:48). In essence, Fellows were asked to fully engage with the nature of the social-ecological purpose and transformative change they were seeking through their own everyday interactions (Nilsson 2015). One cannot expect entire systems to radically shift if one cannot begin to practice and embody a microversion of this in one's everyday conversations with close colleagues (Collins 1988). Although some Fellows struggled to understand how to put inscaping into action in their contexts in the short term, others immediately set about making changes within their organizations. Moreover, survey and interview data later showed the significant impact that the practice of inscaping came to play in the longer term systems change work of the Fellows.

This whole issue of not disconnecting the inside and outside-how does [my organisation] itself need to be a resilient organisation, and what does that actually look like? I'm really bringing this into my conversations with the team, and this will feed into our discussion of what [we] as an agency will look like. 
For many Fellows, this meant shifting how they approached their work and engagements both within and outside their organizations. The commitment to this is demonstrated by reflections from three different Fellows:

The more important part for me, is to try to imitate the ethos we have learned. When you're working with government, there's a lot of hierarchy, rigidity, and authority, and we try to create an environment that is innovative-open, safe, collaborative... The workshops are content-specific and technical, but we also focus a lot on the soft side, drawing on what I've learned from the Fellowship programme.

It's a new way of doing things, a new way of even sitting around in workshops. It"s very different for [the community members], because they're used to someone coming and telling them what to do-even from my side.

The exposure that the Fellowship gives at an individual and cultural level has taught me to approach things in a very open-minded way, to listen, and to take the time to understand people. I've seen that (I'm) having an impact in steering conversations and making sure that everyone is heard in a genuine way. You read this in all these management books and you learn techniques, but they're really empty! It has taught me to really, actually listen - with no assumption about what I want to get out of it.

To summarize, as we worked to create a transformative space to help strengthen the capacity to navigate emergence and enhance system reflexivity, Fellows highlighted at least four key considerations that they valued in putting such capacities into practice. Firstly, awareness of the unpredictable nature of emergence and holding a reflexivity about system dynamics may lead to individuals and their organizations and networks being able to see the complexity of the system in new ways, including the manner in which agency is distributed across the system and the kinds of opportunities opened up by the adjacent possible. Engaging with the diversity of resources, perspectives, actors, and social-ecological relationships is essential-both as a source to create novelty but also because emergence itself will include experiences and confrontations with the "qualitatively different" or the unexpected. However, navigating emergent dynamics and engaging with diversity takes practice. Strategic judgments are made by system entrepreneurs about the opportunity contextswhether it is safe at a precise moment or framed effectively for a local context, or whether the risks of violence or cooptation mean that another dynamic or agent or resource is needed;this is what being reflexive and navigating emergence will require.

\section{CONCLUSION}

There is no shortage of initiatives and programs for individuals who aspire to create change in the world. Promises of innovative solutions and transformational change seem to be omnipresent. However, much of the efforts to innovate and transform are done in the absence of understanding what transformative capacities may actually entail, and many initiatives appear to be businessas-usual or merely building adaptive capacity. Therefore, the Global Fellowship program was our attempt to test a novel approach at building two specific transformative capacities for systems entrepreneurship that remain underexplored: navigating emergence and system reflexivity. We have suggested these as distinct transformative capacities given that transformation will need to lead to a qualitatively different "whole" that is likely to be emergent, and it will require sufficient reflexivity to understand what aspects of the existing system to break down and which to leverage to build an entirely new alternative system. This same level of reflexivity would not be needed in an adaptation that is intended to maintain the existing system. However, we also recognize that at this stage, without controlled experiments, we cannot prove that these are critical, nor do we understand yet what other capacities are essential and how they may or may not be linked to the two we propose here. Therefore, numerous research questions abound for future work that could build on this initial study.

Based on our findings about these two capacities, we conclude with four major reflections. Firstly, the capacity to navigate emergence, which has been demonstrated in this study to include confronting diversity and connecting across scales, can be developed within a transformative learning space by constantly shifting scales - focusing on the individual, the organizational, the network, and more global or macro scales using different lenses and frameworks. The actual experience of rapid scalecrossing can be uncomfortable for most of us, given that each scale may have either different institutional underpinnings or even similar ones but each with their own emergent properties regarding languages, histories, ways of communicating, and worldviews. We suggest that most of us are more comfortable and operate more effectively within one scale. The risk is that this keeps scales siloed and prevents the rewiring of social-ecological systems and the kind of cross-scale reflexivity that we argue is needed to transform systems. Therefore, practicing the experience of shifting scales within a transformative learning space may possibly increase comfort levels or skillfulness at scale-crossing. Data supported this, demonstrating how Fellows began to intentionally build new cross-scale connections with the hope that this would increase the potential for more novelty and innovation.

Secondly, system reflexivity is less of a fixed capacity than it is an ongoing process of inquiry. Thus, we focused on tool, models, and framework simply as heuristics rather than as solutions or best practices. The particular tool that is needed to give a reflexive jolt to a given aspect of complex systems is not predictable, and the work of the system entrepreneur or change agent may require constantly experimenting with these system reflexivity provocations. Trying different tools, frameworks, languages, and more in the various spaces and scales that Fellows may move through, all while making strategic choices about what will illuminate specific institutional dynamics within the shared consciousness of the people within a social-ecological system at any given time, will be a dynamic venture. Pedagogically, we reinforced this by using live case study visits and discussing the Fellows' own work as much as possible. That is, rather than relying only on predigested cases or examples that neatly illustrate a given framework, we also spent a lot of time on the much trickier pedagogy of having people share their work and apply different frameworks to those systems in real time.

Additionally, live cases also helped strengthen the capacity to navigate emergence given that they are dynamically moving, uncontrolled, and unpredictable examples. This form of learning 
was challenging. Fellows often pushed back, expressing a desire for tool kits and wanting prescriptions of when, how, and where to use a given framework. However, as stated regarding what we understand about complex system dynamics and our focus on deepening system reflexivity about people-planet relationships, we have resisted. This did create problems and criticisms. Without the prescriptions and tool kits, we were challenged to make these ideas, experiences, concepts, heuristics, and the transformations capacities that could stem from them available to a large number of people at one time in some sort of open-access platform. This can make it difficult (albeit, not impossible) for Fellows to share what they learn, and calls into question the financial sustainability of such programs. The Fellowship instead is resource intensive, requiring person-person interactions within field sites as an important part of experiential learning. Understanding how to make transformative spaces that are open access to large numbers of people remains an outstanding question that warrants further research.

Finally, social innovation and transformative change can feeland be-dangerous. Emergence by definition is unpredictable. Arguably, systems are generally unreflexive for a reason-so that they can maintain their stability and predictability without major cognitive and emotional effort in their day-to-day enactment. As Westley et al. (2017) highlight, systems react and "fight back" when attempts are made to transform them. If an innovation slides easily into place without a reaction, it likely is not transforming the system. Thus, our findings have begun to show that increasing system reflexivity leads to discomfort, defensiveness, and attack, while emergence ensures that the consequences of a given innovation cannot be known in advance -for the actor, for the people the innovation is trying to help, and for the system as a whole. In a sense then, a transformative learning space is not a safe space at all. It is actually a training ground to move into these more dangerous spaces. It relies on creating a kind of temporary psychological safety in order for people to do the necessary work of unlearning, crossing scales, confronting diversity, and acknowledging positive and negative dynamics, but it also relies on making people uncomfortable enough to prepare them to move through these contested, unknowable systems with courage, resilience, and grace. We leave the last word to one of the Fellows:

I felt emotionally, mentally, and physically stretched beyond anything I had experienced... despite which, I left there feeling more connected to the world and energized and confident to continue being an agent of social change in this complex world ecosystem.

Responses to this article can be read online at: http://www.ecologyandsociety.org/issues/responses. $\mathrm{php} / 10166$

\section{Acknowledgments:}

We would like to acknowledge the inputs of the guest editors and the other authors in this Special Issue who participated in a workshop in South Africa in 2016, as it helped shape our thinking about transformative spaces. The time of $M-L$. Moore and P. Olsson allocated to the drafting of the manuscript was supported by funding from Sida for the GRAID programme at the Stockholm Resilience Centre, Stockholm University. We would also like to acknowledge the Rockefeller Foundation whose financial support made the Fellowship program and the data collection possible. Lastly, we would like to give a special thank you to all of the participants in the Global Fellowship program across the three different cohorts; the space was as transformative for us as we hope it was for you. Thank you for your time in participating in lengthy interviews, surveys, and our constant requests for more data so that we could better understand the many dynamics that matter to the ongoing work of systems change.

\section{LITERATURE CITED}

Abel, C. 1995. External philanthropy and domestic change in Colombian health care: the role of the Rockefeller Foundation, ca. 1920-1950. Hispanic American Historical Review 75 (3):339-376.

Adams, M. 2003. The reflexive self and culture: a critique. British Journal of Sociology 54(2):221-238. http://dx.doi. org/10.1080/0007131032000080212

Akram, S., and A. Hogan. 2015. On reflexivity and the conduct of the self in everyday life: reflections on Bourdieu and Archer. British Journal of Sociology 66(4):605-625. http://dx.doi. org/10.1111/1468-4446.12150

Archer, M. S. 2010. Routine, reflexivity, and realism. Sociological Theory 28(3):272-303. http://dx.doi.org/10.1111/j.1467-9558.2010.01375. $\underline{\mathrm{X}}$

Avelino, F., J. M. Wittmayer, B. Pel, P. Weaver, A. Dumitru, A. Haxeltine, R. Kemp, M. S. Jørgensen, T. Bauler, S. Ruijsink, and T. O'Riordan. 2017. Transformative social innovation and (dis) empowerment. Technological Forecasting and Social Change. http://dx.doi.org/10.1016/j.techfore.2017.05.002

Bang, H. P. 2004. Culture governance: governing self-reflexive modernity. Public Administration 82(1):157-190. http://dx.doi. org/10.1111/j.0033-3298.2004.00389.X

Beck, U., W. Bonss, and C. Lau. 2003. The theory of reflexive modernization: problematic, hypotheses and research programme. Theory, Culture \& Society 20(2):1-33. http://dx.doi. org/10.1177/0263276403020002001

Beck, U., A. Giddens, and S. Lash. 1994. Reflexive modernization: politics, tradition and aesthetics in the modern social order. Polity Press, Cambridge, UK.

Berger, P., and T. Luckmann. 1966. The social construction of knowledge: a treatise in the sociology of knowledge. Doubleday, New York, USA.

Biggs, R., M. Schlüter, D. Biggs, E. L. Bohensky, S. BurnSilver, G. Cundill, V. Dakos, T. M. Daw, L. S. Evans, K. Kotschy, and A. M. Leitch. 2012. Toward principles for enhancing the resilience of ecosystem services. Annual Review of Environment and Resources 37:421-448.

Biggs, R., F. R. Westley, and S. R. Carpenter. 2010. Navigating the back loop: fostering social innovation and transformation in ecosystem management. Ecology and Society 15(2):9. http://dx. doi.org/10.5751/ES-03411-150209 
Bohm, D. 1996. On dialogue. Routledge Press, London, UK.

Brown, K. 2015. Resilience, development, and global change. Routledge Press, London, UK.

Burnes, B. 2004. Emergent change and planned change competitors or allies?: the case of XYZ construction. International Journal of Operations \& Production Management 24 (9):886-902. http://dx.doi.org/10.1108/01443570410552108

Burnes, B. 2005. Complexity theories and organizational change. International Journal of Management Reviews 7(2):73-90. http:// dx.doi.org/10.1111/j.1468-2370.2005.00107.x

Burnes, B. 2015. Understanding resistance to change - building on Coch and French. Journal of Change Management 15 (2):92-116. http://dx.doi.org/10.1080/14697017.2014.969755

Burnes, B., M. Hughes, and R. T. By. 2016. Reimagining organisational change leadership. Leadership 14(2):141-158. http://dx.doi.org/10.1177/1742715016662188

Burns, J. M. 1978. Leadership. Harper Row Publishers, New York, USA. http://dx.doi.org/10.1177/1742715005049347

Cash, D. W., W. N. Adger, F. Berkes, P. Garden, L. Lebel, P. Olsson, L. Pritchard, and O. Young. 2006. Scale and cross-scale dynamics: governance and information in a multilevel world. Ecology and Society 11(2):8. [online] URL: https://www.ecologyandsociety. org/vol11/iss2/art8/

Chapin, F. S., III, S. R. Carpenter, G. P. Kofinas, C. Folke, N. Abel, W. C. Clark, P. Olsson, D. M. Stafford Smith, B. Walker, O. R. Young, F. Berkes, R. Biggs, J. M. Grove, R. L. Naylor, E. Pinkerton, W. Steffen, and F. J. Swanson. 2010. Ecosystem stewardship: sustainability strategies for a rapidly changing planet. Trends in Ecology \& Evolution 25(4):241-249. http://dx. doi.org/10.1016/j.tree.2009.10.008

Collins, R. 1988. The micro contribution to macro sociology. Sociological Theory 6(2):242-253. http://dx.doi.org/10.2307/202118

Colloff, M. J., B. Martín-López, S. Lavorel, B. Locatelli, R. Gorddard, P. Y. Longaretti, G. Walters, L. Van Kerkhoff, C. Wyborn, A. Coreau, and R. M. Wise. 2017. An integrative research framework for enabling transformative adaptation. Environmental Science \& Policy 68:87-96. http://dx.doi. org/10.1016/j.envsci.2016.11.007

Cooperrider, D. L., and S. Srivastva. 1987. Appreciative inquiry in organizational life. Pages 129-169 in R. W. Pasmore and W. A. Woodman, editors. Research in Organizational Change and Development. JAI Press, Greenwich, Connecticut, USA.

Corbin, J., and A. Strauss. 2008. Basics of qualitative research: techniques and procedures for developing grounded theory. Third edition. SAGE Publications, Thousand Oaks, California, USA.

Cordero-Rivera, A. 2017. Behavioral diversity (ethodiversity): a neglected level in the study of biodiversity. Frontiers in Ecology and Evolution 5:7. http://dx.doi.org/10.3389/fevo.2017.00007

Corning, P. A. 2002. The re-emergence of "emergence": a venerable concept in search of a theory. Complexity 7(6):18-30.

Crona, B. I., T. Van Holt, M. Petersson, T. M. Daw, and E. Buchary. 2015. Using social-ecological syndromes to understand impacts of international seafood trade on small-scale fisheries. Global Environmental Change 35:162-175. http://dx.doi. org/10.1016/j.gloenvcha.2015.07.006

Cumming, G. S., D. H. M. Cumming, and C. L. Redman. 2006. Scale mismatches in social-ecological systems: causes, consequences, and solutions. Ecology and Society 11(1):14. http:// dx.doi.org/10.5751/ES-01569-110114

Dickson, R., and M. Saunders. 2014. Developmental evaluation: lessons for evaluative practice from the SEARCH program. Evaluation 20(2):176-194. http://dx.doi.org/10.1177/1356389014527530

DiMaggio, P. J. 1988. Interest and agency in institutional theory. Pages 3-22 in L. G. Zucker, editor. Institutional patterns and organizations. Ballinger, Cambridge, Massachusetts, USA.

Dorado, S. 2005. Institutional entrepreneurship, partaking, and convening. Organization Studies 26(3):385-414. http://dx.doi. org/10.1177/0170840605050873

Eakin, H., X. Rueda, and A. Mahanti. 2017. Transforming governance in telecoupled food systems. Ecology and Society 22 (4):32. http://dx.doi.org/10.5751/ES-09831-220432

Eakin, H., A. York, R. Aggarwal, S. Waters, J. Welch, C. Rubiños, S. Smith-Heisters, C. Bausch, and J. M. Anderies. 2016. Cognitive and institutional influences on farmers' adaptive capacity: insights into barriers and opportunities for transformative change in central Arizona. Regional Environmental Change 16 (3):801-814. http://dx.doi.org/10.1007/s10113-015-0789-y

Eakin, H., A. Winkels, and J. Sendzimir. 2009. Nested vulnerability: exploring cross-scale linkages and vulnerability teleconnections in Mexican and Vietnamese coffee systems. Environmental Science \& Policy 12:398-412. http://dx.doi. org/10.1016/j.envsci.2008.09.003

Ellinor, L., and G. Gerard. 1998. Dialogue: rediscover the transforming power of conversation. John Wiley \& Sons, New York, USA.

Elmqvist, T., C. Folke, M. Nyström, G. Peterson, J. Bengtsson, B. Walker, and J. Norberg. 2003. Response diversity, ecosystem change, and resilience. Frontiers in Ecology and the Environment 1(9):488-494. http://dx.doi.org/10.1890/1540-9295(2003)001[0488: RDECAR]2.0.CO;2

Eriksen, S. H., A. J. Nightingale, and H. Eakin. 2015. Reframing adaptation: the political nature of climate change adaptation. Global Environmental Change 35:523-533.

Feola, G. 2015. Societal transformation in response to global environmental change: a review of emerging concepts. Ambio 44 (5):376-390. http://dx.doi.org/10.1007/s13280-014-0582-Z

Folke, C. 2006. Resilience: the emergence of a perspective for social-ecological systems analyses. Global Environmental Change 16(3):253-267. http://dx.doi.org/10.1016/j.gloenvcha.2006.04.002

Galaz, V., F. Moberg, E. K. Olsson, E. Paglia, and C. Parker. 2011. Institutional and political leadership dimensions of cascading ecological crises. Public Administration 89:361-380. http://dx.doi. org/10.1111/j.1467-9299.2010.01883.x

Galaz, V., J. Tallberg, A. Boin, C. Ituarte-Lima, E. Hey, P. Olsson, and F. R. Westley. 2017. Global governance dimensions of 
globally networked risks: the state of the art in social science research. Risk, Hazards, \& Crises in Public Policy 8(1):4-27. http:// dx.doi.org/10.1002/rhc3.12108

Garud, R., C. Hardy, and S. Maguire. 2007. Institutional entrepreneurship as embedded agency: an introduction to the Special Issue. Organization Studies 28:957-969. http://dx.doi. org/10.1177/0170840607078958

Garud, R., and P. Karnoe. 2005. Distributed agency and interactive emergence. Pages 88-96 in S. W. Floyd, J. Roos, and F. Kellermanns, editors. Innovating Strategy Process. Blackwell Publishing, UK.

Geels, F. W. 2002. Technological transitions as evolutionary reconfiguration processes: a multi-level perspective and a casestudy. Research Policy 31(8-9):1257-1274. http://dx.doi. org/10.1016/S0048-7333(02)00062-8

Giddens, A. 1979. Central problems in social theory: action, structure, and contradiction in social analysis. Vol. 241. University of California Press, Berkeley, California, USA. http://dx.doi. org/10.1007/978-1-349-16161-4

Giddens, A. 1991. The consequences of modernity (Reprint). Polity Press, Cambridge, UK.

Goepel, M. 2016. The great mindshift: how a new economic paradigm and sustainability transformations go hand in hand. Springer, Berlin, Germany. http://dx.doi.org/10.1007/978-3-319-43766-8

Goldstein, J. 1999. Emergence as a construct: history and issues. Emergence 1(1):49-72. http://dx.doi.org/10.1207/s15327000em0101_4

Gual, M. A., and R. B. Norgaard. 2010. Bridging ecological and social systems coevolution: a review and proposal. Ecological Economics 69(4):707-717. http://dx.doi.org/10.1016/j.

ecolecon.2008.07.020

Gunderson, L. H., and C. S. Holling. 2002. Panarchy: understanding transformations in human and natural systems. Washington University Island Press, St. Louis, Missouri, USA.

Hahn, T., P. Olsson, C. Folke, and K. Johansson. 2006. Trustbuilding, knowledge generation and organizational innovations: the role of a bridging organization for adaptive comanagement of a wetland landscape around Kristianstad, Sweden. Human Ecology 34:573-592. http://dx.doi.org/10.1007/s10745-006-9035$\underline{z}$

Harquail, C. V. 2010. For diversity and inclusion, don't treat all differences the same. Blogpost. Authentic Organizations. November 5, 2010. [online] URL: http://authenticorganizations. com/harquail/2010/11/05/dont-treat-every-difference-as-diversity/ \#sthash.VEXEEym6.dpbs

Harrison, D. A., and K. J. Klein. 2007. What's the difference? Diversity constructs as separation, variety, or disparity in organizations. Academy of Management Review 32(4):1199-1228. http://dx.doi.org/10.5465/amr.2007.26586096

Holland, J. H. 2000. Emergence: from chaos to order. Oxford University Press, Oxford, UK.

Isaacs, W. 1999. Dialogue: the art of thinking together. Doubleday, New York, USA.
Jones, E., and S. Rahma. 2009. The Maudsley Hospital and the Rockefeller Foundation: the impact of philanthropy on research and training. Journal of the History of Medicine and Allied Sciences 64(3):273-299.

Kauffman, S. 1995. At home in the Universe. Oxford University Press, New York, USA.

Kauffman, S. 2000. Investigations. Oxford University Press, New York, USA.

Keys, P. W., L. Wang-Erlandsson, and L. J. Gordon. 2016. Revealing invisible water: moisture recycling as an ecosystem service. PLoS ONE 11:e0151993. http://dx.doi.org/10.1371/ journal.pone.0151993

Kolb, A. Y., and D. A. Kolb. 2005. Learning styles and learning spaces: enhancing experiential learning in higher education. Academy of Management Learning \& Education 4(2):193-212. http://dx.doi.org/10.5465/amle.2005.17268566

Lade S. J., A. Tavoni, S. A. Levin, and M. Schlüter. 2013. Regime shifts in a social-ecological system. Theoretical Ecology 6 (3):359-372. http://dx.doi.org/10.1007/s12080-013-0187-3

Lamb, E. 2016. 14 social innovation fellowships you need to know. Blog. Ashoka U, Arlington, Virginia, USA. [online] URL: http:// ashokau.org/blog/14-social-innovation-fellowships-you-need-toknow/

Langlois, M., N. Blanchet-Cohen, and T. Beer. 2012. The art of the nudge: five practices for developmental evaluators. Canadian Journal of Program Evaluation 27(2):39-59.

Lawrence, T. B., and R. Suddaby. 2006. Institutions and institutional work. Pages 215-254 in S. R. Clegg, C. Hardy, T. B. Lawrence, and W. R. Nord, editors. The SAGE Handbook of Organization Studies. Second edition. Sage, London, UK. http:// dx.doi.org/10.4135/9781848608030.n7

Lawrence, T. B., R. Suddaby, and B. Leca. 2009. Introduction: theorizing and studying institutional work. Pages 1-28 in T. B. Lawrence, R. Suddaby, and B. Leca, editors. Institutional work: actors and agency in institutional studies of organization. Cambridge University Press, New York, USA. http://dx.doi. org/10.1017/CBO9780511596605.001

Lawrence, T. B., R. Suddaby, and B. Leca. 2011. Institutional work: refocusing institutional studies of organization. Journal of Management Inquiry 20:52-58. http://dx.doi.org/10.1177/1056492610387222

Luck, G. W., G. C. Daily, and P. R. Ehrlich. 2003. Population diversity and ecosystem services. Trends in Ecology \& Evolution 18:331-336. http://dx.doi.org/10.1016/S0169-5347(03)00100-9

Manson, S. M. 2001. Simplifying complexity: a review of complexity theory. Geoforum 32(3):405-414. http://dx.doi. org/10.1016/S0016-7185(00)00035-X

Marshall, N. A., S. E. Park, W. N. Adger, K. Brown, and S. M. Howden. 2012. Transformational capacity and the influence of place and identity. Environmental Research Letters 7(3):034022. http://dx.doi.org/10.1088/1748-9326/7/3/034022

Mezirow, J. 2000. Learning as transformation: critical perspectives on a theory in progress. Jossey-Bass Higher and Adult Education Series. Jossey-Bass Publishers, San Francisco, California, USA. 
Mitleton-Kelly, E. 2003. Complex systems and evolutionary perspectives on organisations: the application of complexity theory to organisations. Elsevier Science Ltd., Amsterdam, Netherlands.

Moore, M.-L., D. Riddell, and D. Vocisano. 2015. Scaling out, scaling up, scaling deep: strategies of non-profits in advancing systemic social innovation. Journal of Corporate Citizenship 58:67-84. http://dx.doi.org/10.9774/GLEAF.4700.2015.ju.00009

Moore, M. L., O. Tjornbo, E. Enfors, C. Knapp, J. Hodbod, J. A. Baggio, A. Norström, P. Olsson, and D. Biggs. 2014. Studying the complexity of change: toward an analytical framework for understanding deliberate social-ecological transformations. Ecology and Society 19(4):54. http://dx.doi.org/10.5751/ es-06966-190454

Nicholls, A., and S. Teasdale. 2017. Neoliberalism by stealth? Exploring continuity and change within the UK social enterprise policy paradigm. Policy \& Politics 45(3):323-341. http://dx.doi. org/10.1332/030557316X14775864546490

Nilsson, W. O. 2015. Positive institutional maintenance: sustaining engagement in a social purpose organization. Academy of Management Proceedings 2014(1):17534. http://dx.doi. org/10.5465/ambpp.2014.17534abstract

Nilsson, W. O., and T. Paddock. 2014. Social innovation from the inside out. Stanford Social Innovation Review Winter:46-52.

Norström, A V., M. Nyström, J. Lokrantz, and C. Folke. 2009. Alternative states on coral reefs: beyond coral-macroalgal phase shifts. Marine Ecology Progress Series 376:295-306. http://dx.doi. org/10.3354/meps07815

O'Brien, K., 2012. Global environmental change II: from adaptation to deliberate transformation. Progress in Human Geography 36(5):667-676.

Olsson, P. 2017. Synthesis: agency and opportunity. Pages 58-72. in F. R. Westley, K. A. McGowan, and O. Tjornbo, editors. The Evolution of Social Innovation. Edward Elgar Publishing, UK. http://dx.doi.org/10.4337/9781786431158.00009

Olsson, P., C. Folke, and T. Hahn. 2004. Social-ecological transformation for ecosystem management: the development of adaptive co-management of a wetland landscape in southern Sweden. Ecology and Society 9(4):2. [online] URL: http://www. ecologyandsociety.org/vol9/iss4/art2/

Olsson, P., V. Galaz, and W. J. Boonstra. 2014. Sustainability transformations: a resilience perspective. Ecology and Society 19 (4):1. http://dx.doi.org/10.5751/ES-06799-190401

Olsson, P., L. Gunderson, S. Carpenter, P. Ryan, L. Lebel, C. Folke, and C. S. Holling. 2006. Shooting the rapids: navigating transitions to adaptive governance of social-ecological systems. Ecology and Society 11(1):18. http://dx.doi.org/10.5751/ ES-01595-110118

Olsson, P., M.-L. Moore, F. R. Westley, and D. D. P. McCarthy. 2017. The concept of the Anthropocene as a game-changer: a new context for social innovation and transformations to sustainability. Ecology and Society 22(2):31. http://dx.doi. org/10.5751/ES-09310-220231

Ostrom, E. 2005. Doing institutional analysis digging deeper than markets and hierarchies. Pages 819-848 in C. Ménard and M. M.
Shirley, editors. Handbook of New Institutional Economics. Springer, Berlin, Germany.

Page, S. E. 2015. What sociologists should know about complexity. Annual Review of Sociology 41:21-41. http://dx.doi. org/10.1146/annurev-soc-073014-112230

Park, S. E., N. A. Marshall, E. Jakku, A. M. Dowd, S. M. Howden, E. Mendham, and A. Fleming. 2012. Informing adaptation responses to climate change through theories of transformation. Global Environmental Change 22(1):115-126. http://dx.doi. org/10.1016/j.gloenvcha.2011.10.003

Pelling, M., K. O’Brien, and D. Matyas. 2015. Adaptation and transformation. Climatic Change 133(1):113-127.

Polasky, S., S. Carpenter, C. Folke, and B. Beeler. 2011. Decisionmaking under great uncertainty: environmental management in an era of global change. Trends in Ecology \& Evolution 26:398-404. http://dx.doi.org/10.1016/j.tree.2011.04.007

Quinn, J. B. 1985. Managing innovation: controlled chaos. Harvard Business Review 63(May-June):73-84.

Quinn-Patton, M. 2011. Developmental evaluation: applying complexity concepts to enhance innovation and use. Guilford Press, New York, USA.

Quinn-Patton, M., K. McKegg, and N. Wehipeihana. 2016. Developmental evaluation exemplars: principles in practice. Guilford Press, New York, USA.

Reynolds, M., and S. Holwell, editors. 2010. Systems approaches to managing change: a practical guide. Springer, London, UK. http://dx.doi.org/10.1007/978-1-84882-809-4

Rocha, J. C., G.D. Peterson, and R. Biggs. 2015. Regime shifts in the Anthropocene: drivers, risks, and resilience. PLOS ONE 10: e0134639. http://dx.doi.org/10.1371/journal.pone.0134639

Rockström, J., W. Steffen, K. Noone, Å. Persson, F. Stuart Chapin, III, E. F. Lambin, T. M. Lenton, M. Scheffer, C. Folke, H. J. Schellnhuber, B. Nykvist, C. A. De Wit, T. Hughes, S. van der Leeuw, H. Rodhe, S. Sörlin, P. K. Snyder, R. Costanza, U. Svedin, M. Falkenmark, L. Karlberg, R. W. Corell, V. J. Fabry, J. Hansen, B. Walker, D. Liverman, K. Richardson, P. Crutzen, and J. A. Foley. 2009. A safe operating space for humanity. Nature 461:472-475. http://dx.doi.org/10.1038/461472a

Rotmans, J., R. Kemp, M. B. A. van Asselt, F. W. Geels, G. Verbong, and K. Molendijk. 2000. Transitions and transition management: the case of an emission-poor energy supply. (in Dutch). ICIS (International Centre for Integrative Studies), Maastricht, Netherlands.

Sawyer, D. K. 2005. Social emergence: societies as a complex system. Cambridge University Press, Cambridge, UK.

Scharmer, C. O. 2009. Theory U: leading from the future as it emerges. Berrett-Koehler, San Francisco, California, USA.

Scheffer, M., S. Carpenter, J. A. Foley, C. Folke, and B. Walker. 2001. Catastrophic shifts in ecosystems. Nature 413:591-596. http://dx.doi.org/10.1038/35098000

Senge, P., H. Hamilton, and J. Kania. 2015. The dawn of system leadership. Stanford Social Innovation Review 13(1):27-33. 
Seo, M. G., and W. E. D. Creed. 2002. Institutional contradictions, praxis, and institutional change: a dialectical perspective. Academy of Management Review 27:222-247. http://dx.doi. org/10.5465/amr.2002.6588004

Smit, B., and J. Wandel. 2006. Adaptation, adaptive capacity and vulnerability. Global Environmental Change 16(3):282-292.

Smith, A., J. P. Voß, and J. Grin. 2010. Innovation studies and sustainability transitions: the allure of the multi-level perspective and its challenges. Research Policy 39(4):435-448. http://dx.doi. org/10.1016/j.respol.2010.01.023

Steffen, W., W. Broadgate, L. Deutsch, O. Gaffney, and C. Ludwig. 2015. The trajectory of the Anthropocene: The Great Acceleration. Anthropocene Review 2:81-98. http://dx.doi. org/10.1177/2053019614564785

Suddaby, R., T. Viale, and Y. Gendron. 2016. Reflexivity: the role of embedded social position and entrepreneurial social skill in processes of field level change. Research in Organizational Behavior 36:225-245. http://dx.doi.org/10.1016/j.riob.2016.02.001

Sweeney, L. B., and D. Meadows. 2010. The systems thinking playbook. Chelsea Green Publishing, UK.

Taylor, E. W. 2007. An update of transformative learning theory: a critical review of the empirical research (1999-2005). International Journal of Lifelong Education 26(2):173-191. http:// dx.doi.org/10.1080/02601370701219475

Taylor, E. W. 2008. Transformative learning theory. New Directions for Adult \& Continuing Education 2008(119):5-15. http://dx.doi.org/10.1002/ace.301

Torbert, W. R. 1972. Learning from experience: toward consciousness. Columbia University Press, New York, USA.

Tschakert, P., and K. A. Dietrich. 2010. Anticipatory learning for climate change adaptation and resilience. Ecology and Society 15 (2). [online] URL: http://www.ecologyandsociety.org/vol15/iss 2/ $\underline{\operatorname{art} 11 /}$

Uhl-Bien, M., R. Marion, and B. McKelvey. 2007. Complexity leadership theory: shifting leadership from the industrial age to the knowledge era. Leadership Quarterly 18(4):298-318. http://dx. doi.org/10.1016/j.leaqua.2007.04.002

Unger, R. 2013. Keynote speech. Social Frontiers: The Next Edge of Social Innovation Research (Nesta Conference). London, UK. http://www.nesta.org.uk/sites/default/files/professor_unger_social frontiers transcript.pdf

Van de Ven, A. H. 1986. Central problems in the management of innovation. Management Science 32(5):590-607. http://dx.doi. org/10.1287/mnsc.32.5.590

Van Driel, H., and J. Schot. 2005. Radical innovation as a multilevel process: introducing floating grain elevators in the port of Rotterdam. Technology and Culture 46(1):51-76. http://dx.doi. org/10.1353/tech.2005.0011

Vink, J., and K. Koskela-Huotari. 2017. Rethinking reflexivity in institutional theory: taking stock and moving ahead. European Group for Organizational Studies Colloquium, Copenhagen, Denmark.
Vo B, J. P., D. Bauknecht, and R. Kemp, editors. 2006. Reflexive governance for sustainable development. Edward Elgar Publishing.

Westley, F. R. 2013. Social innovation and resilience: how one enhances the other. Stanford Social Innovation Review 11(3):6-8.

Westley, F. R. and N. Antadze. 2010. Making a difference: strategies for scaling social innovation for greater impact. Public Sector Innovation Journal 15:article 2.

Westley, F. R., K. McGowan, and O. Tjornbo, editors. 2017. The evolution of social innovation: building resilience through sustainability transitions. Edward Elgar Publishing, Cheltenham, UK. http://dx.doi.org/10.4337/9781786431158

Westley, F., P. Olsson, C. Folke, T. Homer-Dixon, H. Vredenburg, D. Loorbach, J. Thompson, M. Nilsson, E. Lambin, J. Sendzimir, B. Banerjee, V. Galaz, and S. Van Der Leeuw. 2011. Tipping toward sustainability: emerging pathways of transformation. Ambio 40(7):762-780. http://dx.doi.org/10.1007/s13280-011-0186-9

Westley, F. R., O. Tjornbo, L. Schultz, P. Olsson, C. Folke, B. Crona, and Ö. Bodin. 2013. A theory of transformative agency in linked social-ecological systems. Ecology and Society 18(3):27. http://dx.doi.org/10.5751/es-05072-180327

Wyborn, C., and R. P. Bixler. 2013. Collaboration and nested environmental governance: scale dependency, scale framing, and cross-scale interactions in collaborative conservation. Journal of Environmental Management 123:58-67. http://dx.doi.org/10.1016/ j.jenvman.2013.03.014

Youde, J. 2013. The Rockefeller and Gates Foundations in global health governance. Global Society 27(2):139-158. 